Provided for non-commercial research and education use. Not for reproduction, distribution or commercial use.

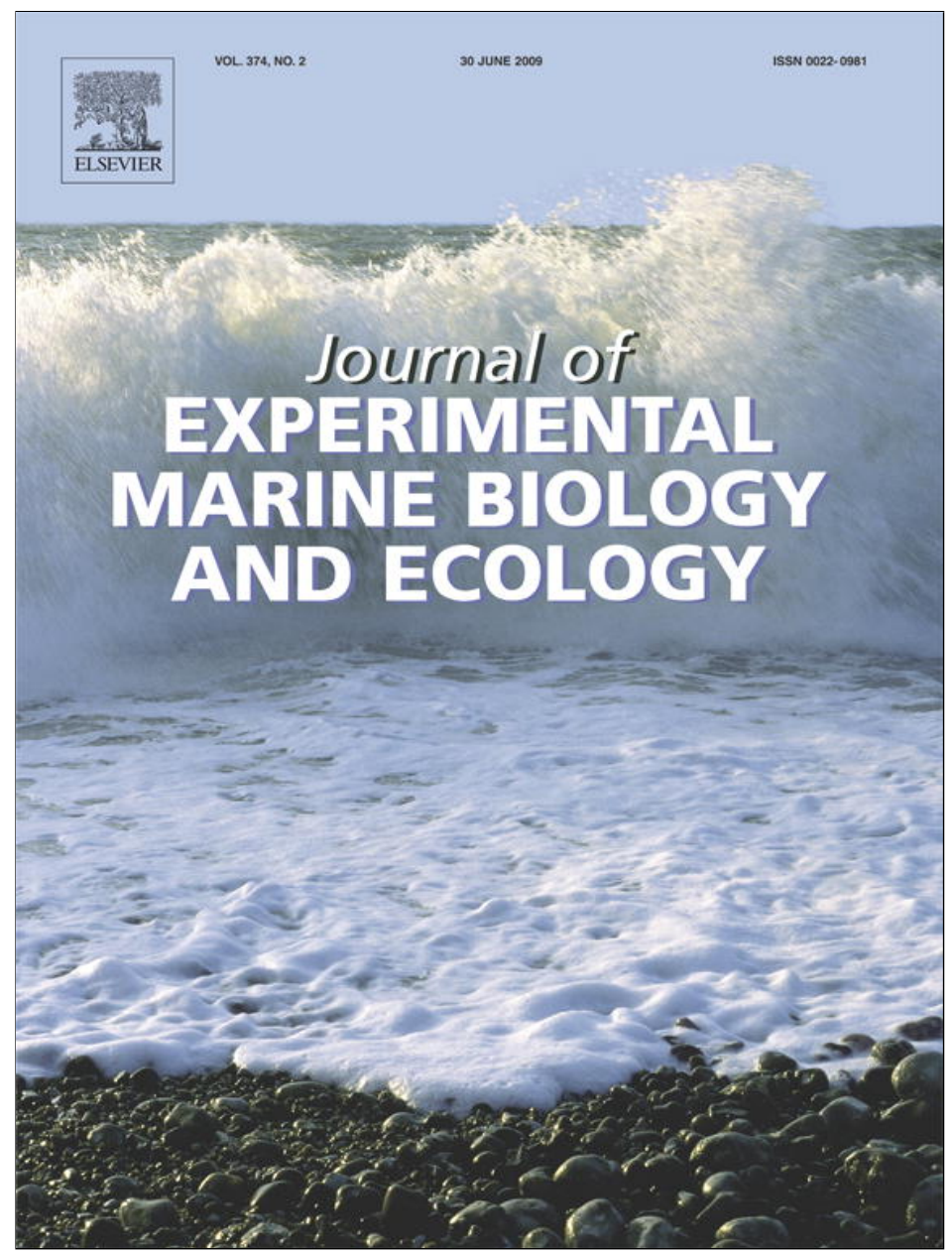

This article appeared in a journal published by Elsevier. The attached copy is furnished to the author for internal non-commercial research and education use, including for instruction at the authors institution and sharing with colleagues.

Other uses, including reproduction and distribution, or selling or licensing copies, or posting to personal, institutional or third party websites are prohibited.

In most cases authors are permitted to post their version of the article (e.g. in Word or Tex form) to their personal website or institutional repository. Authors requiring further information regarding Elsevier's archiving and manuscript policies are encouraged to visit:

http://www.elsevier.com/copyright 


\title{
Bioenergetics of early life-history stages of the brachyuran crab Cancer setosus in response to changes in temperature
}

\author{
Sönke Fischer ${ }^{a}$,*, Sven Thatje ${ }^{b}$, Martin Graeve ${ }^{a}$, Kurt Paschke ${ }^{c}$, Gerhard Kattner $^{a}$ \\ a Alfred Wegener Institute for Polar and Marine Research, Am Handelshafen 12, 27570 Bremerhaven, Germany \\ ${ }^{\mathrm{b}}$ National Oceanography Centre, Southampton, School of Ocean and Earth Science, University of Southampton, European Way, Southampton, SO14 3ZH, United Kingdom \\ c Universidad Austral de Chile, Instituto de Acuicultura, Casilla 1327, Puerto Montt, Chile
}

\section{A R T I C L E I N F O}

\section{Article history:}

Received 26 January 2009

Received in revised form 21 March 2009

Accepted 30 April 2009

\section{Keywords:}

Chile

Crustacea

Eggs

Elemental analysis

Fatty acids

Larvae

\begin{abstract}
A B S T R A C T
In many marine invertebrates, a latitudinal cline in egg size is considered an adaptive response to a decrease in temperature, and enhances the energetic fitness of their larvae at hatching. However, the amount of energy carried over from the egg to the larval stage depends on the metabolic efficiency of egg development. In the present study, eggs of the brachyuran crab Cancer setosus were sampled for their dry mass (DM), carbon $(C)$, nitrogen $(N)$, and fatty acid $(F A)$ content throughout development from blastula stage until hatching of zoea 1-larvae at Antofagasta $\left(23^{\circ} \mathrm{S}\right)$ and Puerto Montt $41^{\circ} \mathrm{S}$ (Chile) under different temperature treatments $\left(12,16\right.$ and $\left.19^{\circ} \mathrm{C}\right)$. Hatching zoea 1 larvae contained $60 \pm 3 \%$ of the initial blastula egg $C$ content, regardless of site or temperature. However, the ontogenetic decrease in egg $C$ content was to a significantly higher extend based on the utilization of energy-rich $F A$ at $12{ }^{\circ} \mathrm{C}(-1.16 \mu \mathrm{g} / \mathrm{egg})$ compared to the $19{ }^{\circ} \mathrm{C}$ treatments in Antofagasta and Puerto Montt $\left(-0.63\right.$ to $-0.73 \mu \mathrm{g}$ FA per egg). At $19{ }^{\circ} \mathrm{C}$ egg-metabolism was based to a substantial extend on protein, which allowed for the saving of energy-richer lipids. We conclude that the production of larger eggs with high FA content appears to be adaptive not only to fuel the larval development, but is also a response to the prolonged egg developmental times at lower temperatures.

(c) 2009 Elsevier B.V. All rights reserved.
\end{abstract}

\section{Introduction}

Intraspecific variability in egg energy provision along (latitudinal) temperature clines has been reported for a broad variety of marine invertebrates (Clarke, 1992; Hadfield and Strathmann, 1996). The prevalent pattern, namely the production of larger eggs at higher latitudes (Pandian, 1994; Yampolsky and Schreiner, 1996), is discussed to be an adaptive response to the mismatch of unpredictable food availability and prolonged development faced by the emerging larvae at lower temperatures (Thatje et al., 2005). In the brachyuran crab Cancer setosus (Molina, 1782), which spans in distribution from Southern Ecuador to Central Southern Chile $\left(2^{\circ} \mathrm{S}, 079^{\circ} \mathrm{W}-46^{\circ} \mathrm{S}\right.$, $075^{\circ} \mathrm{W}$ ) (Rathbun, 1930) energetic investment per egg (measured as dry mass $(D M)$, carbon $(C)$ and nitrogen content $(N)$, volume $(V))$ is negatively correlated to the temperature experienced by the female crab in the time prior egg-laying (Fischer et al., 2009). Eggs produced close to the species lower temperature limit at $\sim 11^{\circ} \mathrm{C}$ in Puerto Montt (Central Southern Chile, $41^{\circ} \mathrm{S}$ ) were about one third higher in $D M, C$, $N$, and $V$ than eggs produced by equal sized females under conditions representative for the species upper temperature range at $\sim 19{ }^{\circ} \mathrm{C}$ in Antofagasta (Northern Chile, $23^{\circ} \mathrm{S}$ ) (Fischer et al., 2009). In support of

\footnotetext{
* Corresponding author. Tel.: +49 4714831 1643; fax: +49 47148311149. E-mail address: soenke.fischer@gmx.de (S. Fischer).
}

these patterns, $C$. setosus larvae from Antofagasta were successfully reared until their fifth zoea stage at 16 and $20{ }^{\circ} \mathrm{C}$, but failed to successfully complete development at lower temperatures representative for Puerto Montt $\left(12{ }^{\circ} \mathrm{C}\right.$ ) (Weiss et al., in press). However, to assess the adaptive significance of both latitudinal and intraspecific differences in egg energy provision one has to define to which extend these differences are carried over into later life-history stages. With regard to this, traits of emerging larvae are not exclusively determined by maternal egg energy provision, but can furthermore be constrained by the physico-chemical environment (e.g. salinity, oxygen, temperature) experienced throughout egg incubation period (Kunisch and Anger, 1984; Pandian, 1994; Giménez, 2002, 2006). Egg development is hastened with temperature rise, but often at the cost of an altered metabolic efficiency (Heming, 1982; Pandian, 1994). This energetic cost may lead to a size reduction of the zoea 1 larvae, as shown for the spider crab Hyas araneus, the Dungeness crab Cancer magister, the caridean shrimps Nauticaris magellanica, Betaeus emarginatus, and Pandalus borealis, which in laboratory cultures hatched significantly smaller at higher temperatures of egg development (Kunisch and Anger, 1984; Shirley et al., 1987; Wehrtmann and Kattner, 1998; Wehrtmann and Lopez, 2003; Brillon et al., 2005). Such pattern has also been supported by field collected larvae of Nauticaris magellanica (Thatje and Bacardit, 2000). In the spiny lobster Jasus edwardsii and the crayfish Cherax quadricarinatus an increase in egg incubation temperature led to a higher consumption of lipids and certain fatty 
acids (mainly 20:5(n-3)) (Smith et al., 2002; García-Guerrero et al., 2003). On the other hand, in the American lobster Homarus americanus less lipids were utilized with higher egg incubation temperature (Sasaki et al., 1986). Lipids and fatty acids contribute about $20-30 \%$ to egg-composition (protein $15-25 \%$, salts $2-5 \%$, remainder water), and frequently form the most important source of metabolic energy in decapod crustacean eggs (Pandian, 1994). Fat oxidization contributes 67,75 , and $88 \%$ of the metabolic energy in Eupagurus bernhardus, Crangon crangon and Homarus gammarus eggs, respectively (Pandian and Schumann, 1967; Pandian, 1967, 1970). However, in the egg development of two boreo-arctic cirripede species (Balanus balanoides, B. balanus) and the deepwater giant crab Pseudocarcinus gigas protein was utilized in preference over lipid (Barnes, 1965; Gardner, 2001).

The aims of the present study are to

(i) compare fatty acid (FA) content of blastula eggs produced in the field at conditions close to the species upper and lower temperature limit (Antofagasta and Puerto Montt, respectively) and in captivity in Antofagasta

(ii) assess changes in egg traits $(D M, C, N, V, F A)$ throughout embryogenesis until larvae hatching at both locations

(iii) elucidate the adaptive importance of latitudinal variation in egg traits in biogeography and evolution of marine invertebrates.

\section{Materials and methods}

\subsection{Sampling and maintenance}

Ovigerous C. setosus were caught by divers at 5-10 m water depth at different sites around Antofagasta, Northern Chile $\left(23^{\circ} \mathrm{S}, 70^{\circ} \mathrm{W} ; 11 /\right.$ 2005 and 01/2006) and in Carelmapu, close to Puerto Montt in Central Southern Chile $\left(41^{\circ} \mathrm{S}, 73^{\circ} \mathrm{W}, 09 / 2006\right.$ and $\left.11 / 2006\right)$. Females bearing early blastula stage eggs, as identified microscopically by their uniform distribution of yolk and absence of cleavage, were transferred to aquaria at both locations.

Incubation temperatures were chosen to represent the lower and upper range of egg development in normal "non-El Niño" years at both locations: ovigerous females were held in a recirculation system at $16{ }^{\circ} \mathrm{C}$ and in a flow through system at $19{ }^{\circ} \mathrm{C}$ in Antofagasta and in recirculation systems at temperatures of 12 and $16^{\circ} \mathrm{C}$ in Puerto Montt. In Puerto Montt, a third group of ovigerous crabs was transferred to a recirculation aquaria system at $19{ }^{\circ} \mathrm{C}$ in order to represent Antofagasta conditions. Salinity ranged between 30 and 34. Crabs were individually labelled with a small plastic tag glued onto their carapace and were fed ad libitum with living mussels Perumytilus purpuratus. Every 2 days eggs were taken with fine forceps from the border of the egg masses to assess their developmental stage. As described by Fischer and Thatje (2008), C. setosus produced several subsequent egg masses in captivity. Three females with eggs laid in captivity in Antofagasta in the flow through aquaria were sampled as ovigerous crabs from the field. Eggs in four successive developmental stages and recently hatched zoea 1 larvae were sampled for elemental analysis $(D M, C, N)$ and eggs in stages I and IV for fatty acid composition (fatty acids were also sampled for stages II and III for eggs produced in captivity in Antofagasta). Samples were kept frozen at $-80{ }^{\circ} \mathrm{C}$. Egg and zoea stages were defined as:

I. Blastula - no yolk used; approximately 1 to 2 days after oviposition

II. Gastrula - $25 \%$ of the yolk used, still no eyes visible (not sampled in Puerto Montt)

III. Eye-placode - eyes are visible as kidney-shaped small dark spots, but still no chromatophores present and no heartbeat

IV. Pre-hatching - all yolk utilized, eyes completely roundish, chromatophores well developed, heart beats vigorously and embryo moves inside the egg-shell, 1 to 2 days before larvae hatching

V. Zoea 1, collected immediately after hatching in a fine sieve which was connected to the overflow of the aquaria.

To assess if aquaria had an effect on the bioenergetic traits of hatching larvae independent of temperature at both locations $3 \mathrm{fe}-$ males caught in the field with advanced stage IV eggs were transferred to the laboratory and their larvae sampled after a short incubation period.

\subsection{Elemental analysis and egg volume}

For elemental analysis after Anger and Dawirs (1982) five aliquot samples of 50 eggs or zoea 1 larvae per female were counted under a stereomicroscope, then briefly rinsed in distilled water and subsequently transferred to pre-weighted tin cartridges. Samples were freeze dried overnight at $<0.01$ mbar using a lyophilizer (Lyovac) and their dry mass $(D M)$ was measured with a microbalance (Sartorius M2P) to the nearest $\mu$ g. Subsequently, samples were combusted at $1020{ }^{\circ} \mathrm{C}$ in an elemental analyzer (Hekatech Euro EA) for the determination of $C$ and $N$ content using acetanilide as a standard. Lengths $\left(D_{1}\right)$ and widths $\left(D_{2}\right)$ of 20 eggs per female were measured with a microscope which was equipped with a calibrated eye-piece micrometer, and their volume was calculated based on the formula for oblate spheroids: $V=\left(\pi^{*} D_{1}^{2} * D_{2}\right) / 6$ (Turner and Lawrence, 1979).

\subsection{Fatty acid analysis}

Fatty acid analysis was based on 200 eggs per sample (stages I and IV) to reach necessary sample size. As internal standard 19:0 methyl ester was added and the samples were crushed by ultrasonification in dichloromethane:methanol $(2: 1, \mathrm{v}: \mathrm{v})$. Samples were transesterified with $3 \%$ concentrated sulphuric acid in methanol for $4 \mathrm{~h}$ at $80^{\circ} \mathrm{C}$. After extraction of fatty acid methyl esters with hexane, the fatty acid composition was analyzed with a gas-liquid chromatograph (HP GC6890) equipped with a capillary column (30 $\mathrm{m} \times 0.25 \mathrm{~mm}$ (i.d.); liquid phase DB-FAB; film thickness: $0.25 \mu \mathrm{m}$ ) using temperature programming following Kattner and Fricke (1986) (for overview of samples taken see Table 1).

\subsection{Data analysis}

The net changes in egg traits throughout development, meaning the respective differences in $D M, C, N$, and $F A$ between stages I and IV eggs of the same female, were tested for significant differences between treatments with ANOVA (based on the means of the five

\section{Table 1}

C. setosus: overview of ovigerous females sampled throughout egg development (stages: I blastula, II gastrula, III eye-placode and IV pre-hatching) until hatching of the zoea 1 at different temperatures of incubation and number of replicates used for the ANOVAs.

\begin{tabular}{|c|c|c|c|}
\hline$T$ & Egg stages I, III, IV & Egg stages I, IV & Zoea 1 larvae \\
\hline$\left({ }^{\circ} \mathrm{C}\right)$ & $D M, C, N, V$ & fatty acids & $D M, C, N$ \\
\hline \multicolumn{4}{|l|}{ Antofagasta } \\
\hline $16 \pm 0.5$ & $3(+\mathrm{II})$ & & 3 \\
\hline $19 \pm 0.8$ & $3(+\mathrm{II})$ & 3 & 3 \\
\hline $19 \pm 0.8$ "captivity" & $3(+\mathrm{II})$ & $3(+$ II, III $)$ & 3 \\
\hline \multicolumn{4}{|l|}{ Puerto Montt } \\
\hline $12 \pm 0.3$ & 6 & 6 & 3 \\
\hline $16 \pm 0.5$ & 2 & & 2 \\
\hline $19 \pm 0.3$ & 3 & 3 & 1 \\
\hline
\end{tabular}


Table 2

C. setosus: sampling days after oviposition, elemental composition $D M, C, N\left(\mu \mathrm{g}\right.$ ind $\left.^{-1}\right)$, $C: N$ ratio and volume of eggs $\left(V, \mathrm{~mm}^{3} \times 10^{-4}\right)$ from blastula stage (I) to pre-hatching stage (IV) until zoea 1 larvae hatching (Z1) in Antofagasta and Puerto Montt (arithmetic mean values $\pm \mathrm{SD}$ ); for number of replicates see Table 1 .

\begin{tabular}{|c|c|c|c|c|c|c|}
\hline Stage days & & $D M$ & C & $N$ & $C: N$ & V \\
\hline \multicolumn{7}{|c|}{ Antofagasta $16{ }^{\circ} \mathrm{C}$} \\
\hline I & $\sim 2.0$ & $9.6 \pm 0.2$ & $5.1 \pm 0.1$ & $0.99 \pm 0.02$ & 5.2 & $176 \pm 06$ \\
\hline II & $15.0 \pm 1.7$ & $9.6 \pm 0.3$ & $5.0 \pm 0.2$ & $1.02 \pm 0.04$ & 4.9 & $194 \pm 09$ \\
\hline III & $22.3 \pm 1.2$ & $9.6 \pm 0.4$ & $4.9 \pm 0.1$ & $0.98 \pm 0.03$ & 5.0 & $226 \pm 32$ \\
\hline IV & $37.0 \pm 1.0$ & $8.7 \pm 0.2$ & $4.0 \pm 0.1$ & $1.02 \pm 0.02$ & 4.0 & $330 \pm 08$ \\
\hline $\mathrm{Z1}$ & $38.7 \pm 1.5$ & $10.0 \pm 0.7$ & $3.1 \pm 0.1$ & $0.80 \pm 0.03$ & 3.8 & \\
\hline \multicolumn{7}{|c|}{ Antofagasta $19{ }^{\circ} \mathrm{C}$} \\
\hline I & $\sim 2.0$ & $10.2 \pm 1.5$ & $5.4 \pm 0.7$ & $1.13 \pm 0.13$ & 4.8 & $181 \pm 18$ \\
\hline II & $13.0 \pm 1.0$ & $10.3 \pm 1.2$ & $5.3 \pm 0.6$ & $1.04 \pm 0.12$ & 5.1 & $206 \pm 23$ \\
\hline III & $20.3 \pm 0.6$ & $10.2 \pm 1.4$ & $5.0 \pm 0.7$ & $1.07 \pm 0.12$ & 4.7 & $289 \pm 03$ \\
\hline IV & $28.0 \pm 1.0$ & $9.9 \pm 1.5$ & $4.4 \pm 0.7$ & $1.09 \pm 0.17$ & 4.0 & $357 \pm 52$ \\
\hline $\mathrm{Z1}$ & $30.0 \pm 1.0$ & $9.4 \pm 0.4$ & $3.2 \pm 0.3$ & $0.77 \pm 0.07$ & 4.1 & \\
\hline \multicolumn{7}{|c|}{ Antofagasta $19{ }^{\circ} \mathrm{C}$ "captivity” } \\
\hline I & 2.0 & $10.0 \pm 0.4$ & $5.3 \pm 0.2$ & $1.06 \pm 0.06$ & 5.0 & $174 \pm 08$ \\
\hline II & $14.0 \pm 0.0$ & $10.1 \pm 0.5$ & $5.2 \pm 0.2$ & $1.10 \pm 0.07$ & 4.7 & $214 \pm 21$ \\
\hline III & $20.0 \pm 0.0$ & $7.5 \pm 0.7$ & $3.8 \pm 0.3$ & $0.83 \pm 0.09$ & 3.4 & $197 \pm 09$ \\
\hline IV & $28.0 \pm 0.6$ & $7.2 \pm 0.7$ & $3.3 \pm 0.3$ & $0.79 \pm 0.06$ & 3.1 & $276 \pm 12$ \\
\hline $\mathrm{Z1}$ & $30.7 \pm 0.6$ & $8.6 \pm 0.1$ & $3.0 \pm 0.3$ & $0.75 \pm 0.03$ & 4.1 & \\
\hline \multicolumn{7}{|c|}{ Puerto Montt $12{ }^{\circ} \mathrm{C}$} \\
\hline I & $\sim 2.0$ & $12.0 \pm 0.1$ & $6.4 \pm 0.4$ & $1.21 \pm 0.06$ & 5.3 & $219 \pm 16$ \\
\hline III & $36.0 \pm 5.1$ & $11.6 \pm 0.7$ & $6.0 \pm 0.4$ & $1.22 \pm 0.10$ & 4.9 & $296 \pm 46$ \\
\hline IV & $59.7 \pm 4.3$ & $10.9 \pm 0.8$ & $5.0 \pm 0.3$ & $1.19 \pm 0.08$ & 4.2 & $437 \pm 30$ \\
\hline $\mathrm{Z1}$ & $66.0 \pm 0.6$ & $12.4 \pm 1.4$ & $4.0 \pm 0.4$ & $0.95 \pm 0.08$ & 4.2 & \\
\hline \multicolumn{7}{|c|}{ Puerto Montt $16{ }^{\circ} \mathrm{C}$} \\
\hline I & $\sim 2.0$ & $13.1 \pm 1.1$ & $7.2 \pm 0.6$ & $1.37 \pm 0.10$ & 5.2 & $263 \pm 16$ \\
\hline III & $15.0 \pm 0.0$ & $13.3 \pm 1.1$ & $7.1 \pm 0.6$ & $1.41 \pm 0.09$ & 5.0 & $295 \pm 57$ \\
\hline IV & $29.0 \pm 1.4$ & $12.1 \pm 0.9$ & $5.8 \pm 0.6$ & $1.26 \pm 0.09$ & 4.6 & $418 \pm 35$ \\
\hline $\mathrm{Z1}$ & $31.5 \pm 3.5$ & $11.5 \pm 0.2$ & $4.5 \pm 0.4$ & $0.95 \pm 0.07$ & 4.7 & \\
\hline \multicolumn{7}{|c|}{ Puerto Montt $19{ }^{\circ} \mathrm{C}$} \\
\hline I & $\sim 2.0$ & $13.1 \pm 1.4$ & $7.1 \pm 0.7$ & $1.37 \pm 0.13$ & 5.2 & $251 \pm 29$ \\
\hline III & $15.7 \pm 2.5$ & $13.0 \pm 1.4$ & $6.9 \pm 0.9$ & $1.38 \pm 0.16$ & 5.0 & $291 \pm 19$ \\
\hline IV & $30.3 \pm 5.5$ & $12.3 \pm 1.3$ & $5.7 \pm 0.7$ & $1.28 \pm 0.14$ & 4.5 & $457 \pm 90$ \\
\hline $\mathrm{Z1}$ & 26.0 & 10.4 & 4.4 & 1.04 & 4.2 & \\
\hline
\end{tabular}

parallel $D M, C$, and $N$ measurements with "female" as sampling level). Homogeneity of variances was tested with Levene's test and normality of residuals with the Shapiro-Wilk test (Sokal and Rohlf, 1995). Differences among treatments after a significant ANOVA were tested with the Tukey HSD test. Consecutive egg stages of females were tested for differences with a paired Student's $t$-test, or when normality was not given, with a Wilcoxon signed rank test.

\section{Results}

\subsection{Elemental composition and volume}

Within the first two developmental stages from blastula (I) to gastrula (II), covering about 2 weeks of development, no significant changes in dry mass $(D M)$, carbon $(C)$, and nitrogen content $(N)$ were observed in eggs in Antofagasta (Table 2, data combined for all treatments, paired Student's $t$-test, $\alpha=0.01$ ). Therefore, the gastrula stage was not sampled in following experiments in Puerto Montt.

In general, ontogenetic changes in egg $D M, C$, and $N$ followed a similar temporal pattern between locations and temperature treatments (except for Antofagasta $19{ }^{\circ} \mathrm{C}$ "captivity") (Table 2). From the blastula stage (I) to the eye-placode stage (III) only minor changes in $D M$ and $C$, and insignificant changes in $N$ occurred (combined for all treatments, Wilcoxon signed rank test, $p=0.812$ )(Table 2). Until prehatching (IV), DM decreased by $0.3-1.1 \mu \mathrm{g}$ ind $^{-1}, C$ decreased by about $20 \%$, while $N$ remained quite stable. The net changes in $D M$ and $C$ from stages I to IV did not differ significantly for the three temperature treatments in Puerto Montt (ANOVA) (Table 3). From pre-hatching to the zoea 1 larvae, $C$ again decreased by about $20 \%$ and $N$ decreased by $20-30 \%$ (Table 3, Fig. 1 ).

The pattern was different for Antofagasta "captivity" produced eggs, where a pronounced decrease in $D M, C$, and $N$ occurred as early as the eye-placode stage (III). Nevertheless, the hatching zoea 1 larvae were comparable in their quantitative $D M, C$, and $N$ content to zoea 1 larvae from eggs produced in nature in Antofagasta (incubated at 16 and $19{ }^{\circ} \mathrm{C}$ ) (Table 2). Throughout development, eggs increased by $60-$ $100 \%$ in volume.

\subsection{Fatty acid composition}

The quantitatively most important fatty acids in the blastula stage were the saturate (SAT) 16:0, the monounsaturates (MUFA) 16:1 $(n-7)$ and 18:1(n-9), and the polyunsaturates (PUFA) 20:5(n-3) and 22:6(n-3) contributing to about $2 / 3$ of the total of fatty acids (Tables 4 and 5). Despite for palmitic acid (16:0), which was the most abundant fatty acid in all treatments, small differences between fatty acids at both locations were found. In descending order, in Puerto Montt 18:1 (n-9), 20:5(n-3), 16:1(n-7) and 22:6(n-3) were the quantitatively most prominent fatty acids following 16:0. In "field-produced" eggs in Antofagasta the order was identical with the exception of 20:5(n-3) showing higher quantities than 18:1(n-9) and for the "captivity eggs" 22:6(n-3) was quantitatively the second most important fatty acid. Overall, PUFA were the most abundant fatty acids in blastula eggs (37$40 \%)$, followed by MUFA (32-37\%) and SAT (25-28\%) (Table 5). As indicated by the $C$ content, little ontogenetic changes in fatty acid content occurred until the eye-placode stage (III) (see Antofagasta "captivity"; Tables 3 and 4).

From blastula to pre-hatching SAT changed little on the percentage basis, MUFA decreased over-proportionally, and the percentage share of polyunsaturated fatty acids increased. The marked decrease in MUFA is largely explained by a pronounced utilization of 16:1(n-7) (decrease of 58-84\%), and to a lesser extend of 18:1(n-9) and 18:1(n-7) (Table 4). Within PUFA, especially 20:5 (n-3) and 22:6 (n-3) were less utilized than other fatty acids, and thus showed an increase in their relative contribution in the pre-hatching stage (IV) (Table 5).

Fatty acids made up between 13.3 and $15.5 \%$ of the blastula egg DM and 25.0 to $28.9 \%$ of blastula $C$ content (Table 6). In the pre-hatching stage (IV) the percentage share of fatty acids dropped to $14.6-15.7 \%$ of C, except for Puerto Montt ( $19{ }^{\circ} \mathrm{C}$ incubation), where fatty acids still contributed $20.3 \%$ to the $C$ content. Overall, $60 \%$ of the initial fatty acid was consumed throughout development at Puerto Montt at $12{ }^{\circ} \mathrm{C}, 55$ and $48 \%$ for "field" and "captivity eggs" in Antofagasta at $\sim 19{ }^{\circ} \mathrm{C}$, respectively, and no more than $35 \%$ in Puerto Montt at $19{ }^{\circ} \mathrm{C}$. The

Table 3

C. setosus: percentage changes in elemental composition (DM, $C, N)$, and volume $(V)$ during egg development from stage I (blastula) to stage IV (pre-hatching) and from stage I to freshly hatched zoea 1 larvae (Z1) (calculated solely for females with zoea 1 sampled).

\begin{tabular}{|c|c|c|c|c|c|c|c|}
\hline \multirow{2}{*}{$\frac{T}{{ }^{\circ} \mathrm{C}}$} & \multicolumn{4}{|c|}{ Stage IV as $\%$ of stage I } & \multicolumn{3}{|c|}{$\mathrm{Z1}$ as \% of stage I } \\
\hline & $\overline{D M}$ & $C$ & $N$ & V & $\overline{D M}$ & $C$ & $N$ \\
\hline \multicolumn{8}{|l|}{$\overline{\text { Antofagasta }}$} \\
\hline 16 & $90^{\mathrm{A}}$ & $78^{\mathrm{ABC}}$ & $103^{C}$ & 187 & 104 & 60 & 81 \\
\hline 19 & $96^{\mathrm{BC}}$ & $81^{\mathrm{BC}}$ & $96^{\mathrm{ABC}}$ & 197 & 92 & 59 & 69 \\
\hline 19 "captivity" & $72^{\mathrm{C}}$ & $62^{C}$ & $75^{\mathrm{BC}}$ & 158 & 87 & 57 & 70 \\
\hline \multicolumn{8}{|l|}{ Puerto Montt } \\
\hline 12 & $91^{\mathrm{A}}$ & $78^{\mathrm{A}}$ & $98^{\mathrm{BC}}$ & 200 & 101 & 61 & 77 \\
\hline 16 & $92^{\mathrm{A}}$ & $82^{\mathrm{AB}}$ & $92^{\mathrm{A}}$ & 159 & 87 & 62 & 69 \\
\hline 19 & $94^{\mathrm{AB}}$ & $81^{\mathrm{AB}}$ & $94^{\mathrm{AB}}$ & 182 & 75 & 58 & 72 \\
\hline
\end{tabular}

The results of ANOVA, testing for the differences ( $\mu$ g ind ${ }^{-1}$ ) between stages I and IV eggs as shown by raised letters. Different letters indicate significant differences (Tukey HSD at $\alpha=0.05$ ). For number of replicates see Table 1 . 


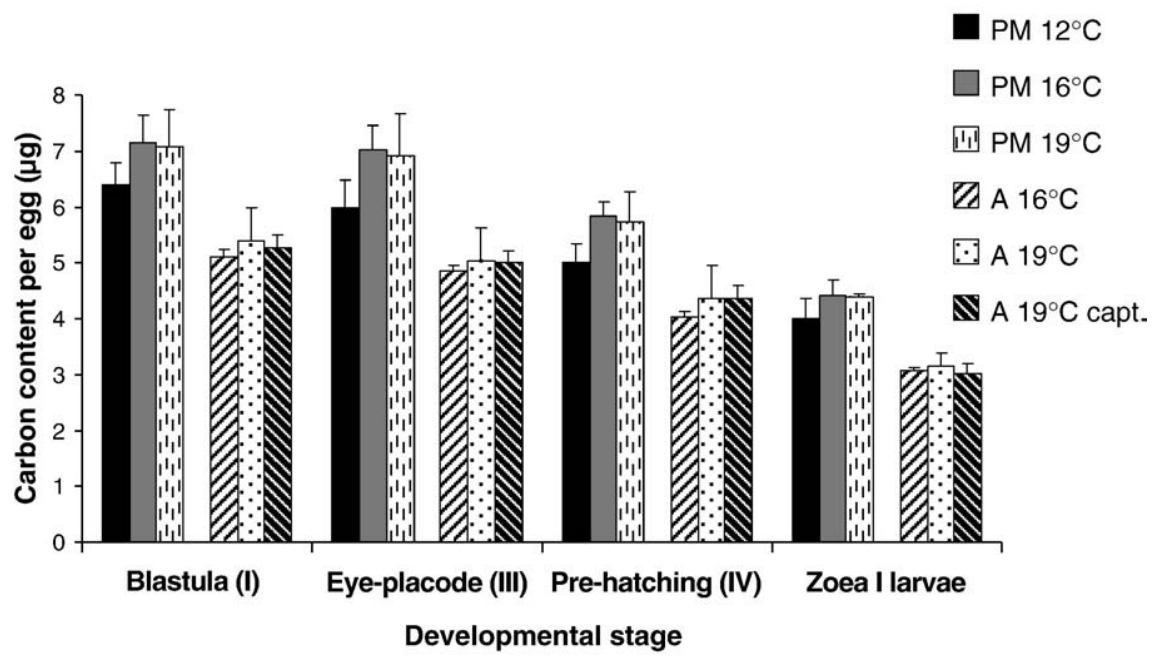

Fig. 1. C. setosus. Carbon content throughout egg development and in freshly hatched zoea 1 larvae in Puerto Montt (PM) and Antofagasta (A) at different incubation temperatures. With the exception of "A $19{ }^{\circ} \mathrm{C}$ capt." all eggs were produced in the field.

absolute decrease in $F A$ was significantly larger at $12{ }^{\circ} \mathrm{C}$ than at $19{ }^{\circ} \mathrm{C}$ in Puerto Montt and $19{ }^{\circ} \mathrm{C}$ in Antofagasta "captivity" (ANOVA).

\section{Discussion}

\subsection{Elemental composition and volume}

The temporal sequence of egg energy-utilization by the early life stages of $C$. setosus followed the pattern of low losses in carbon until the beginning of the heartbeat (transition stages III-IV) and an accelerated utilization of egg-nutrients thereafter (Gardner, 2001). The observed increase in egg volume (58-100\%) throughout embryogenesis is a consequence of osmotic water uptake and, to a lesser extend of the retention of metabolic water (Pandian, 1970; Amsler and George, 1984; Rosa et al., 2007). Egg DM is negatively affected by utilization of energy reserves through respiration and positively, at least for marine Crustacea, by the uptake of salts and minerals (Green, 1965; Pandian, 1967). Because of these two antagonistic processes, which accelerate with development, egg $D M$ and energy measures based on $D M$ (e.g. fatty acid content/DM), are not the most suitable

Table 4

C. setosus: absolute fatty acid composition ( $\mu \mathrm{g} / 200$ eggs) in egg stages I-IV in Antofagasta captivity $\left(19^{\circ} \mathrm{C}\right)$ and in stages I and IV for field-produced eggs in Antofagasta $\left(19^{\circ} \mathrm{C}\right)$ and Puerto Montt $\left(12\right.$ and $\left.19{ }^{\circ} \mathrm{C}\right) \pm$ SD.

\begin{tabular}{|c|c|c|c|c|c|c|c|c|c|c|}
\hline \multirow[t]{2}{*}{ Fatty acid } & \multicolumn{4}{|c|}{$\mathrm{A}$ (capt.) $\sim 19{ }^{\circ} \mathrm{C}(n=3)$} & \multicolumn{2}{|c|}{$\mathrm{A}$ (field) $\sim 19{ }^{\circ} \mathrm{C}(n=3)$} & \multicolumn{2}{|c|}{ PM $19{ }^{\circ} \mathrm{C}(n=3)$} & \multicolumn{2}{|c|}{ PM $12{ }^{\circ} \mathrm{C}(n=6)$} \\
\hline & $\bar{I}$ & II & III & IV & $\bar{I}$ & IV & $\bar{I}$ & IV & $\bar{I}$ & IV \\
\hline $14: 0$ & $3.9 \pm 1.0$ & $3.4 \pm 0.8$ & $2.5 \pm 1.0$ & $1.0 \pm 0.1$ & $6.5 \pm 1.7$ & $1.0 \pm 0.6$ & $6.1 \pm 0.9$ & $2.6 \pm 0.2$ & $6.4 \pm 1.0$ & $0.9 \pm 0.3$ \\
\hline $15: 0$ & $3.3 \pm 0.7$ & $3.0 \pm 0.4$ & $2.3 \pm 0.5$ & $1.1 \pm 0.1$ & $1.8 \pm 0.3$ & $0.5 \pm 0.3$ & $3.0 \pm 0.9$ & $1.5 \pm 0.5$ & $1.8 \pm 0.5$ & $0.4 \pm 0.1$ \\
\hline $16: 0$ & $48.4 \pm 6.0$ & $45.6 \pm 2.5$ & $37.3 \pm 3.9$ & $21.9 \pm 1.1$ & $49.1 \pm 11.3$ & $19.0 \pm 10.2$ & $59.0 \pm 4.4$ & $36.1 \pm 5.8$ & $62.3 \pm 7.8$ & $21.2 \pm 2.7$ \\
\hline $17: 0$ & $3.0 \pm 0.5$ & $2.9 \pm 0.3$ & $2.6 \pm 0.3$ & $1.8 \pm 0.2$ & $1.5 \pm 0.1$ & $0.5 \pm 0.5$ & $2.4 \pm 0.4$ & $2.0 \pm 0.7$ & $1.7 \pm 0.5$ & $1.0 \pm 0.2$ \\
\hline 18:0 & $13.8 \pm 1.7$ & $14.0 \pm 1.1$ & $12.9 \pm 1.3$ & $11.6 \pm 0.9$ & $15.1 \pm 2.2$ & $9.0 \pm 1.3$ & $17.4 \pm 0.3$ & $15.3 \pm 2.8$ & $19.6 \pm 6.2$ & $9.3 \pm 0.9$ \\
\hline $20: 0$ & $0.5 \pm 0.0$ & $0.7 \pm 0.0$ & $0.8 \pm 0.0$ & $0.9 \pm 0.0$ & $1.1 \pm 0.2$ & $1.0 \pm 0.2$ & $1.6 \pm 0.7$ & $1.6 \pm 0.4$ & $1.7 \pm 0.6$ & $1.1 \pm 0.2$ \\
\hline$\sum \mathrm{SFA}$ & 73.0 & 69.7 & 58.5 & 38.2 & 75.0 & 31.0 & 89.5 & 59.1 & 93.5 & 33.9 \\
\hline $16: 1(n-7)$ & $26.3 \pm 6.3$ & $20.6 \pm 3.8$ & $14.8 \pm 3.2$ & $5.4 \pm 1.1$ & $36.7 \pm 12.7$ & $7.6 \pm 7.0$ & $42.9 \pm 10.2$ & $18.2 \pm 5.3$ & $35.4 \pm 8.9$ & $5.5 \pm 1.4$ \\
\hline $18: 1(n-9)$ & $30.0 \pm 1.1$ & $28.7 \pm 0.9$ & $23.4 \pm 1.3$ & $13.6 \pm 0.7$ & $38.5 \pm 11.7$ & $14.7 \pm 8.7$ & $51.7 \pm 9.5$ & $30.0 \pm 6.7$ & $56.3 \pm 10.9$ & $17.2 \pm 4.6$ \\
\hline $18: 1(n-7)$ & $14.4 \pm 0.7$ & $14.0 \pm 1.0$ & $11.9 \pm 1.1$ & $7.7 \pm 0.2$ & $17.6 \pm 2.1$ & $8.3 \pm 3.1$ & $24.1 \pm 6.1$ & $16.9 \pm 5.3$ & $29.0 \pm 2.9$ & $12.1 \pm 1.5$ \\
\hline $20: 1(n-7)$ & $4.1 \pm 0.2$ & $4.0 \pm 0.2$ & $3.3 \pm 0.2$ & $1.8 \pm 0.1$ & $3.5 \pm 0.6$ & $1.2 \pm 0.7$ & $5.2 \pm 1.8$ & $2.3 \pm 0.7$ & $6.1 \pm 1.5$ & $1.6 \pm 0.5$ \\
\hline $20: 1(n-9)$ & $8.5 \pm 0.3$ & $8.3 \pm 0.5$ & $7.2 \pm 0.5$ & $3.9 \pm 0.3$ & $2.8 \pm 0.3$ & $1.2 \pm 0.4$ & $3.7 \pm 1.4$ & $3.5 \pm 0.9$ & $5.0 \pm 0.9$ & $1.8 \pm 0.8$ \\
\hline $20: 1(n-11)$ & $2.7 \pm 0.4$ & $2.6 \pm 0.2$ & $2.1 \pm 0.1$ & $0.9 \pm 0.1$ & $3.2 \pm 1.7$ & $1.0 \pm 1.0$ & $5.5 \pm 2.9$ & $1.4 \pm 1.2$ & $4.9 \pm 2.4$ & $1.0 \pm 0.5$ \\
\hline $22: 1(n-7)$ & $1.1 \pm 0.1$ & $1.1 \pm 0.0$ & $0.9 \pm 0.2$ & $0.6 \pm 0.1$ & $4.0 \pm 1.6$ & $2.3 \pm 1.6$ & $2.4 \pm 0.7$ & $1.7 \pm 0.3$ & $4.6 \pm 2.6$ & $1.6 \pm 1.0$ \\
\hline$\sum$ MUFA & 87.0 & 79.3 & 63.6 & 33.9 & 106.3 & 36.2 & 135.6 & 74.0 & 141.4 & 40.8 \\
\hline $16: 2(n-4)$ & $0.6 \pm 0.3$ & $0.5 \pm 0.4$ & $0.4 \pm 0.3$ & $0.1 \pm 0.0$ & $1.7 \pm 1.1$ & $0.2 \pm 0.1$ & $1.5 \pm 0.1$ & $1.2 \pm 1.0$ & $1.2 \pm 0.5$ & $0.2 \pm 0.0$ \\
\hline $16: 3(n-4)$ & $10.4 \pm 6.4$ & $10.7 \pm 6.7$ & $5.3 \pm 5.5$ & $4.0 \pm 0.8$ & $4.3 \pm 2.7$ & $1.5 \pm 1.9$ & $2.9 \pm 0.3$ & $1.5 \pm 0.4$ & $2.4 \pm 0.8$ & $0.5 \pm 0.2$ \\
\hline $18: 2(n-6)$ & $3.9 \pm 0.2$ & $3.7 \pm 0.2$ & $2.9 \pm 0.2$ & $1.5 \pm 0.1$ & $3.0 \pm 0.5$ & $1.0 \pm 0.4$ & $2.3 \pm 0.4$ & $1.2 \pm 0.4$ & $4.9 \pm 3.2$ & $1.0 \pm 1.0$ \\
\hline $18: 3(n-3)$ & $2.2 \pm 0.3$ & $1.9 \pm 0.2$ & $1.4 \pm 0.2$ & $0.5 \pm 0.0$ & $6.1 \pm 1.3$ & $4.7 \pm 0.9$ & $6.6 \pm 1.4$ & $5.4 \pm 1.1$ & $5.9 \pm 0.5$ & $4.7 \pm 0.5$ \\
\hline $18: 4(n-3)$ & $1.0 \pm 0.1$ & $0.8 \pm 0.1$ & $0.6 \pm 0.2$ & $0.2 \pm 0.0$ & $1.0 \pm 0.2$ & $0.2 \pm 0.2$ & $1.2 \pm 0.3$ & $0.6 \pm 0.3$ & $1.6 \pm 0.3$ & $0.3 \pm 0.1$ \\
\hline $20: 2(n-6)$ & $1.3 \pm 0.1$ & $1.3 \pm 0.3$ & $1.2 \pm 0.2$ & $1.0 \pm 0.2$ & $2.3 \pm 1.0$ & $1.6 \pm 0.9$ & $2.5 \pm 0.9$ & $2.3 \pm 0.8$ & $3.3 \pm 0.5$ & $1.9 \pm 0.4$ \\
\hline $20: 4(n-6)$ & $11.2 \pm 0.8$ & $10.9 \pm 0.3$ & $9.3 \pm 0.2$ & $7.2 \pm 0.5$ & $12.4 \pm 3.5$ & $7.0 \pm 4.4$ & $9.2 \pm 4.3$ & $6.8 \pm 3.7$ & $7.3 \pm 2.3$ & $3.9 \pm 0.9$ \\
\hline $20: 4(n-3)$ & $0.9 \pm 0.1$ & $0.8 \pm 0.1$ & $0.7 \pm 0.1$ & $0.3 \pm 0.1$ & $1.3 \pm 0.1$ & $0.2 \pm 0.1$ & $1.8 \pm 0.8$ & $0.8 \pm 0.3$ & $2.8 \pm 1.5$ & $0.4 \pm 0.2$ \\
\hline $20: 5(n-3)$ & $29.1 \pm 3.9$ & $28.6 \pm 2.9$ & $25.1 \pm 2.5$ & $23.9 \pm 2.0$ & $42.5 \pm 15.5$ & $23.8 \pm 1.9$ & $50.4 \pm 14.6$ & $39.4 \pm 9.3$ & $54.8 \pm 8.8$ & $31.9 \pm 4.0$ \\
\hline $22: 5(n-3)$ & $5.0 \pm 0.8$ & $4.7 \pm 0.6$ & $3.9 \pm 0.4$ & $2.3 \pm 0.4$ & $7.4 \pm 4.6$ & $5.5 \pm 2.4$ & $16.4 \pm 1.8$ & $11.0 \pm 3.6$ & $15.0 \pm 5.0$ & $7.2 \pm 3.2$ \\
\hline $22: 6(n-3)$ & $39.5 \pm 2.3$ & $37.6 \pm 3.0$ & $32.8 \pm 1.9$ & $23.4 \pm 1.0$ & $21.6 \pm 4.2$ & $14.1 \pm 2.3$ & $35.7 \pm 8.1$ & $29.5 \pm 9.9$ & $36.0 \pm 7.9$ & $20.0 \pm 4.5$ \\
\hline$\sum$ PUFA & 105.1 & 101.4 & 83.5 & 64.6 & 103.5 & 59.7 & 130.6 & 99.9 & 135.1 & 71.9 \\
\hline$\sum$ Total & 265.1 & 250.3 & 205.5 & 136.7 & 284.9 & 127.0 & 355.7 & 232.9 & 370.0 & 146.5 \\
\hline \multicolumn{4}{|c|}{$\%$ of the total stage I FA left in stage IV } & 51.6 & & 44.6 & & 65.5 & & 39.6 \\
\hline
\end{tabular}

SFA: saturated fatty acids, MUFA: monounsaturated fatty acids, PUFA: polyunsaturated fatty acids. 
Table 5

C. setosus: relative fatty acid composition (\% of total fatty acids) in egg stages I-IV in Antofagasta captivity $\left(19^{\circ} \mathrm{C}\right.$ ) and in stages I and IV for field-produced eggs in Antofagasta ( $19{ }^{\circ} \mathrm{C}$ ) and Puerto Montt $\left(12\right.$ and $\left.19{ }^{\circ} \mathrm{C}\right) \pm$ SD.

\begin{tabular}{|c|c|c|c|c|c|c|c|c|c|c|}
\hline \multirow[t]{2}{*}{ Fatty acid } & \multicolumn{4}{|c|}{$\mathrm{A}$ (capt.) $\sim 19{ }^{\circ} \mathrm{C}(n=3)$} & \multicolumn{2}{|c|}{ A (field) $\sim 19{ }^{\circ} \mathrm{C}(n=3)$} & \multicolumn{2}{|c|}{ PM $19{ }^{\circ} \mathrm{C}(n=3)$} & \multicolumn{2}{|c|}{$\mathrm{PM} 12{ }^{\circ} \mathrm{C}(n=6)$} \\
\hline & $\mathrm{I}$ & II & III & IV & $\mathrm{I}$ & IV & $\mathrm{I}$ & IV & I & IV \\
\hline$\overline{14: 0}$ & $1.5 \pm 0.2$ & $1.3 \pm 0.2$ & $1.2 \pm 0.3$ & $0.7 \pm 0.0$ & $2.3 \pm 0.6$ & $0.7 \pm 0.1$ & $1.7 \pm 0.3$ & $1.1 \pm 0.2$ & $1.7 \pm 0.1$ & $0.6 \pm 0.2$ \\
\hline $15: 0$ & $1.2 \pm 0.1$ & $1.2 \pm 0.1$ & $1.1 \pm 0.1$ & $0.8 \pm 0.0$ & $0.6 \pm 0.1$ & $0.4 \pm 0.1$ & $0.8 \pm 0.2$ & $0.6 \pm 0.2$ & $0.6 \pm 0.4$ & $0.3 \pm 0.1$ \\
\hline $16: 0$ & $18.3 \pm 0.9$ & $18.2 \pm 0.4$ & $18.1 \pm 0.3$ & $16.1 \pm 0.1$ & $17.1 \pm 1.7$ & $14.5 \pm 2.1$ & $16.6 \pm 0.2$ & $15.5 \pm 0.4$ & $17.2 \pm 0.9$ & $14.5 \pm 0.7$ \\
\hline $17: 0$ & $1.1 \pm 0.1$ & $1.2 \pm 0.0$ & $1.2 \pm 0.0$ & $1.3 \pm 0.1$ & $0.5 \pm 0.1$ & $0.5 \pm 0.5$ & $0.7 \pm 0.1$ & $0.8 \pm 0.2$ & $0.6 \pm 0.3$ & $0.7 \pm 0.2$ \\
\hline 18:0 & $5.2 \pm 0.1$ & $5.6 \pm 0.1$ & $6.3 \pm 0.1$ & $8.5 \pm 0.5$ & $5.4 \pm 1.0$ & $7.5 \pm 1.5$ & $4.9 \pm 0.5$ & $6.5 \pm 0.1$ & $5.3 \pm 1.0$ & $6.4 \pm 0.4$ \\
\hline $20: 0$ & $0.2 \pm 0.0$ & $0.3 \pm 0.0$ & $0.4 \pm 0.1$ & $0.7 \pm 0.0$ & $0.4 \pm 0.0$ & $0.8 \pm 0.1$ & $0.5 \pm 0.2$ & $0.7 \pm 0.1$ & $0.4 \pm 0.2$ & $0.7 \pm 0.1$ \\
\hline$\sum \mathrm{SFA}$ & 27.5 & 27.8 & 28.4 & 28.0 & 26.4 & 24.4 & 25.2 & 25.4 & 25.9 & 23.2 \\
\hline $16: 1(n-7)$ & $9.9 \pm 2.3$ & $8.2 \pm 1.2$ & $7.2 \pm 1.1$ & $4.0 \pm 0.6$ & $12.7 \pm 2.8$ & $5.3 \pm 2.9$ & $12.0 \pm 0.3$ & $7.8 \pm 1.7$ & $9.5 \pm 1.7$ & $3.7 \pm 0.8$ \\
\hline $18: 1(n-9)$ & $11.4 \pm 0.7$ & $11.5 \pm 1.0$ & $11.5 \pm 1.1$ & $10.0 \pm 0.4$ & $13.4 \pm 2.5$ & $11.0 \pm 2.3$ & $14.5 \pm 2.0$ & $12.9 \pm 1.8$ & $14.3 \pm 2.1$ & $11.6 \pm 2.1$ \\
\hline $18: 1(n-7)$ & $5.4 \pm 0.5$ & $5.6 \pm 0.7$ & $5.6 \pm 0.6$ & $5.6 \pm 0.4$ & $6.2 \pm 0.4$ & $6.5 \pm 0.3$ & $6.8 \pm 1.4$ & $7.2 \pm 1.4$ & $7.4 \pm 1.4$ & $8.2 \pm 0.4$ \\
\hline $20: 1(n-11)$ & $1.0 \pm 0.1$ & $0.6 \pm 0.1$ & $1.0 \pm 0.0$ & $1.0 \pm 0.1$ & $1.1 \pm 0.4$ & $0.7 \pm 0.5$ & $1.6 \pm 1.0$ & $0.5 \pm 0.5$ & $1.4 \pm 0.6$ & $0.7 \pm 0.4$ \\
\hline $20: 1(n-9)$ & $3.2 \pm 0.3$ & $2.9 \pm 0.2$ & $3.3 \pm 0.4$ & $3.5 \pm 0.4$ & $1.0 \pm 0.2$ & $0.9 \pm 0.1$ & $1.0 \pm 0.3$ & $1.6 \pm 0.7$ & $1.6 \pm 0.6$ & $1.2 \pm 0.4$ \\
\hline $20: 1(n-7)$ & $1.6 \pm 0.1$ & $1.8 \pm 0.2$ & $1.6 \pm 0.2$ & $1.3 \pm 0.0$ & $1.2 \pm 0.1$ & $0.9 \pm 0.2$ & $1.5 \pm 0.6$ & $1.0 \pm 0.2$ & $1.6 \pm 0.4$ & $1.1 \pm 0.4$ \\
\hline $22: 1(n-7)$ & $0.4 \pm 0.1$ & $0.4 \pm 0.0$ & $0.4 \pm 0.1$ & $0.4 \pm 0.0$ & $1.4 \pm 0.4$ & $1.7 \pm 1.2$ & $0.7 \pm 0.2$ & $0.7 \pm 0.1$ & $1.1 \pm 0.6$ & $1.0 \pm 0.6$ \\
\hline$\sum$ MUFA & 32.9 & 31.7 & 31.0 & 24.8 & 32.0 & 27.1 & 38.1 & 31.8 & 36.9 & 27.7 \\
\hline $16: 2(n-4)$ & $0.2 \pm 0.1$ & $0.2 \pm 0.2$ & $0.2 \pm 0.1$ & $0.1 \pm 0.0$ & $0.6 \pm 0.5$ & $0.2 \pm 0.1$ & $0.4 \pm 0.1$ & $0.6 \pm 0.6$ & $0.3 \pm 0.1$ & $0.1 \pm 0.0$ \\
\hline $16: 3(n-4)$ & $3.9 \pm 2.2$ & $4.2 \pm 2.5$ & $2.4 \pm 2.3$ & $3.0 \pm 0.5$ & $1.5 \pm 0.7$ & $0.9 \pm 0.9$ & $0.8 \pm 0.0$ & $0.6 \pm 0.1$ & $1.4 \pm 1.9$ & $0.3 \pm 0.1$ \\
\hline $18: 2(n-6)$ & $1.5 \pm 0.1$ & $1.5 \pm 0.1$ & $1.4 \pm 0.0$ & $1.1 \pm 0.0$ & $1.1 \pm 0.0$ & $0.8 \pm 0.0$ & $0.6 \pm 0.1$ & $0.5 \pm 0.1$ & $1.4 \pm 0.6$ & $0.7 \pm 0.6$ \\
\hline $18: 3(n-3)$ & $0.8 \pm 0.0$ & $0.8 \pm 0.1$ & $0.7 \pm 0.0$ & $0.4 \pm 0.0$ & $2.1 \pm 0.1$ & $3.9 \pm 0.8$ & $1.8 \pm 0.2$ & $2.3 \pm 0.1$ & $1.5 \pm 0.4$ & $3.3 \pm 0.7$ \\
\hline $18: 4(n-3)$ & $0.4 \pm 0.0$ & $0.3 \pm 0.0$ & $0.3 \pm 0.0$ & $0.1 \pm 0.0$ & $0.3 \pm 0.1$ & $0.1 \pm 0.1$ & $0.3 \pm 0.1$ & $0.3 \pm 0.2$ & $0.4 \pm 0.1$ & $0.2 \pm 0.1$ \\
\hline $20: 2(n-6)$ & $0.5 \pm 0.1$ & $0.5 \pm 0.1$ & $0.6 \pm 0.1$ & $0.7 \pm 0.2$ & $0.8 \pm 0.3$ & $1.2 \pm 0.2$ & $0.7 \pm 0.3$ & $1.0 \pm 0.3$ & $0.8 \pm 0.2$ & $1.3 \pm 0.2$ \\
\hline $20: 4(n-6)$ & $4.2 \pm 0.2$ & $4.4 \pm 0.2$ & $4.5 \pm 0.3$ & $5.3 \pm 0.2$ & $4.3 \pm 0.9$ & $5.2 \pm 1.4$ & $2.5 \pm 1.1$ & $2.9 \pm 1.3$ & $2.3 \pm 1.0$ & $2.6 \pm 0.4$ \\
\hline $20: 4(n-3)$ & $0.4 \pm 0.0$ & $0.3 \pm 0.1$ & $0.3 \pm 0.0$ & $0.2 \pm 0.0$ & $0.5 \pm 0.0$ & $0.2 \pm 0.1$ & $0.5 \pm 0.3$ & $0.4 \pm 0.2$ & $0.7 \pm 0.5$ & $0.3 \pm 0.1$ \\
\hline $20: 5(n-3)$ & $10.9 \pm 0.4$ & $11.4 \pm 0.7$ & $12.2 \pm 0.1$ & $17.5 \pm 0.7$ & $15.2 \pm 5.6$ & $20.1 \pm 5.7$ & $14.3 \pm 4.2$ & $17.1 \pm 4.0$ & $14.0 \pm 2.1$ & $21.8 \pm 1.4$ \\
\hline $22: 5(n-3)$ & $1.9 \pm 0.2$ & $1.9 \pm 0.1$ & $1.0 \pm 0.1$ & $1.7 \pm 0.2$ & $2.5 \pm 1.4$ & $4.2 \pm 0.7$ & $4.6 \pm 0.6$ & $4.8 \pm 1.2$ & $3.9 \pm 2.1$ & $4.9 \pm 2.2$ \\
\hline $22: 6(n-3)$ & $14.9 \pm 0.9$ & $15.0 \pm 1.2$ & $16.0 \pm 1.4$ & $17.1 \pm 0.6$ & $7.7 \pm 2.0$ & $11.7 \pm 2.3$ & $10.0 \pm 1.6$ & $12.4 \pm 2.3$ & $10.4 \pm 2.2$ & $13.6 \pm 2.4$ \\
\hline$\sum$ PUFA & 39.6 & 40.5 & 40.6 & 47.2 & 36.6 & 48.5 & 36.7 & 42.9 & 37.2 & 49.1 \\
\hline
\end{tabular}

SFA: saturated fatty acids, MUFA: monounsaturated fatty acids, PUFA: polyunsaturated fatty acids.

measures of energy content of late stage eggs (Jaeckle, 1995). In this respect, $D M$ of recently hatched zoea 1 larvae varied between $75 \%$ and $104 \%$ of that of early blastula stage eggs, while the $C$ content of the zoea 1 larvae was $60 \pm 3 \%$ of the blastula stage, irrespective of location and incubation temperature (Table 3). Comparably, the zoea 1 of the estuarine crab Chasmagnathus granulata hatches with $60-66 \%$ of their initial blastula $C$ content depending on the salinity conditions encountered throughout embryogenesis (Giménez and Anger, 2001). The decreasing $C: N$ ratio during egg development indicates that lipids, as in most other Crustacea, were preferably used as energy source over proteins (which are rich in N) (Holland, 1978; Clarke et al., 1990; Petersen and Anger, 1997; Giménez and Anger, 2001).

The reason why eggs produced in captivity in Antofagasta showed an earlier and more pronounced decrease in $C$ and $N$ than eggs of females produced in nature, both incubated parallel under the same conditions, is by no means clear and needs further investigation. Strikingly, larvae hatched with similar $D M, C$, and $N$ content after the same duration of development (Table 2). Furthermore, zoea 1 larvae that were hatched from advanced stage IV eggs obtained from the field were highly comparable in their $D M, C$, and $N$ content to larvae from aquaria incubated eggs (Antofagasta: $D M 9.1 \pm 1.2 \mu \mathrm{g}, C 3.1 \pm$ $0.1 \mu \mathrm{g}$ and $N 0.77 \pm 0.03 \mu \mathrm{g}$; Puerto Montt: $D M 11.7 \pm 0.8 \mu \mathrm{g}, C \mathrm{C} .3 \pm$ $0.3 \mu \mathrm{g}$; and $N 1.05 \pm 0.03 \mu \mathrm{g}$ ) (see Table 2 ).

\subsection{Fatty acid composition}

MUFA were utilized at a higher rate in $C$. setosus than SAT and PUFA, confirming the previous described pattern for the hippolytidid shrimp Lysmata seticaudata, the European lobster Homarus gammarus, and the grapsid crab Armases cinereum (Morais et al., 2002; Calado et al., 2005; Rosa et al., 2005; Figueiredo et al., 2008b). The 16:1(n-7) fatty acid declined particularly strongly (by $79 \%$ in Antofagasta; 58 and $84 \%$ in Puerto Montt at 19 and $12^{\circ}$ ) (Fig. 2), as also reported for Nauticaris magellanica (Wehrtmann and Kattner, 1998). SAT and
MUFA are usually major fatty acids of triacylglycerols which are storage lipids in most organisms. Their decrease during egg development shows clearly the utilization for energetic requirements. In contrast, PUFA are necessary for cell differentiation and thus for the membrane formation during embryogenesis. This is in agreement with the observed quantitative retaining of the $n$-3 PUFA, eicosapentaenoic acid (EPA, 20:5(n-3)) and docosahexaenoic acid (DHA, 22:6 $(n-3))$. In addition, the importance of these fatty acids has been attributed to maintaining membrane flexibility (Chapelle, 1986; Morais et al., 2002; Figueiredo et al., 2008a). For copepods a seasonal increase in body DHA content was interpreted as mechanism to maintain membrane fluidity at lower temperatures (Farkas, 1979). In the present study, eggs sampled in the field had higher proportions of EPA than DHA. Eggs produced in Puerto Montt $\left(\sim 11^{\circ} \mathrm{C}\right)$ showed a slightly higher percentage of DHA (10\%) than eggs produced under warmer conditions in Antofagasta $\left(\sim 19{ }^{\circ} \mathrm{C} ; 8 \%\right.$ DHA). The elevated proportions of EPA and moreover of 16:1(n-7) reflect a dietary input based primarily on a diatom source (Dalsgaard et al., 2003). However, eggs produced in captivity at $19{ }^{\circ} \mathrm{C}$ had the highest proportion of DHA (15\%) and thus do not fit into this latitudinal pattern (Table 5). The

Table 6

C. setosus: Fatty acid content (FA $\mu \mathrm{g} / \mathrm{egg})$ and as percentage of $D M$ and $C$ in egg stages I and IV.

\begin{tabular}{|c|c|c|c|c|c|c|}
\hline \multirow[t]{2}{*}{$T\left({ }^{\circ} \mathrm{C}\right)$} & \multicolumn{2}{|c|}{$F A \mu \mathrm{g} / \mathrm{egg}$} & \multicolumn{2}{|c|}{$F A$ as \% of $D M$} & \multicolumn{2}{|c|}{$F A$ as $\%$ of $C$} \\
\hline & I & IV & I & $\overline{\mathrm{IV}}$ & I & IV \\
\hline \multicolumn{7}{|l|}{ Antofagasta } \\
\hline 19 "captivity" & 1.33 & 0.68 & 13.3 & 7.1 & 25.2 & 15.7 \\
\hline 19 & 1.42 & 0.63 & 13.9 & 6.4 & 26.5 & 14.6 \\
\hline \multicolumn{7}{|l|}{ Puerto Montt } \\
\hline 19 & 1.78 & 1.16 & 13.6 & 9.5 & 25.0 & 20.3 \\
\hline 12 & 1.85 & 0.73 & 15.5 & 6.7 & 28.9 & 14.6 \\
\hline
\end{tabular}




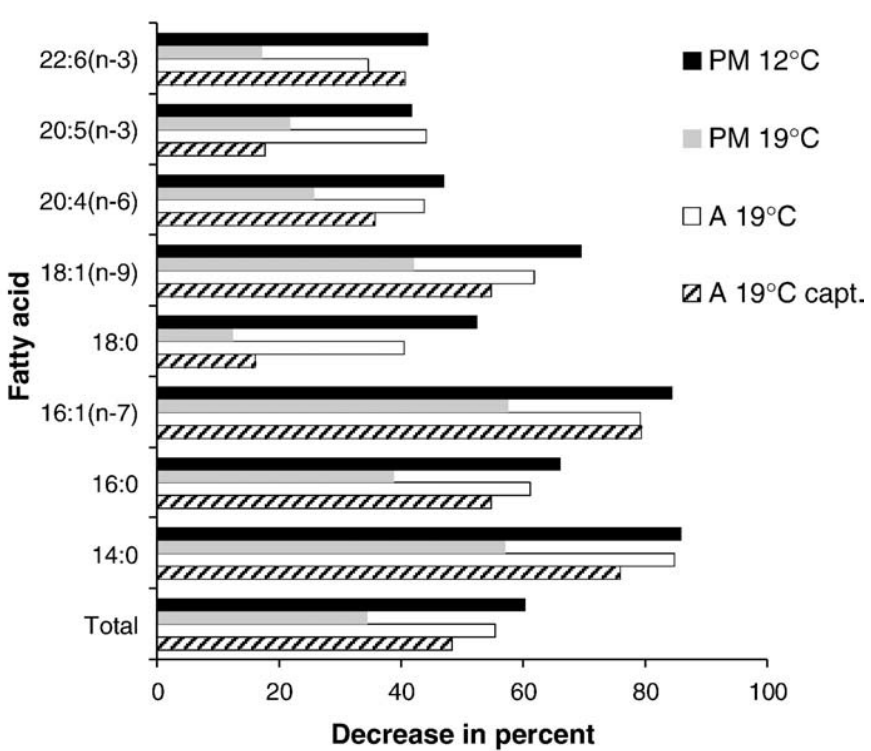

Fig. 2. C. setosus. Percentage change in the total of fatty acids and in the most abundant fatty acids from the start (stage I) to the end of the incubation period (stage IV) at 12 and $19{ }^{\circ} \mathrm{C}$ in Puerto Montt (PM) and at $19{ }^{\circ} \mathrm{C}$ in Antofagasta (A; field and captivity produced eggs). Decrease in percent refers to changes in the absolute mass ( $\mu \mathrm{g})$ per fatty acid.

eggs produced in captivity originated from females that prior to egglaying, were fed exclusively on Perumytilus purpuratus, which may be the source of DHA. These PUFA are essential in Crustacea since they cannot be synthesised de novo (Anger, 2001), and thus are a reflection of the female food intake. They are considered an important part of crustacean and finfish-broodstock diet, leading to enhanced eggquality (Harrison, 1990; Wiegand, 1996; Brooks et al., 1997).

\subsection{Adaptive importance of latitudinal variation in egg traits}

Although eggs at all three temperatures in Puerto Montt showed a similar decrease of $1.4 \mu \mathrm{g}$ carbon from blastula to pre-hatching (Table 4; Fig. 1), almost twice as much fatty acids were utilized at $12{ }^{\circ} \mathrm{C}$ $(-1.15 \mu \mathrm{g} / \mathrm{egg})$ compared to $19{ }^{\circ} \mathrm{C}(-0.62 \mu \mathrm{g} / \mathrm{egg})$ (Table 6). Since lipids composed of fatty acids make up about $80 \%$ of the total lipid fraction, the remaining decrease in carbon content must largely be based on utilization of proteins. On a mass-basis protein contains about $40 \%$ less energy than lipids. The utilization of protein may lead to a saving of the energetically richer lipids.

The most pronounced utilization of fatty acids took place at $12^{\circ} \mathrm{C}$ in Puerto Montt (-60\%), which is a typical temperature of egg incubation for this location close to the species southern distributional range (Fischer and Thatje, 2008). Blastula eggs at Puerto Montt at $12{ }^{\circ} \mathrm{C}$ were provided by $30 \%$ more fatty acids as blastula eggs produced in Antofagasta at $19^{\circ} \mathrm{C}$. This advantage is largely compensated by the prolonged larval development at the lower temperature. However, when exposed to the higher Antofagasta temperatures $\left(19^{\circ} \mathrm{C}\right)$, eggs from Puerto Montt maintain their higher initial investment in fatty acids throughout development.

This clearly indicates an increased conversion efficiency of embryos incubated at higher temperatures in C. setosus, as reported also for the American lobster Homarus americanus (Sasaki et al., 1986). In this respect, at least for $C$. setosus the production of larger, energyricher eggs at the colder location, is not solely an adaptation to the prolonged development faced by the hatching larvae (Weiss et al., in press), but also a necessity to meet the energetic demands of the prolonged egg development.

\section{Conclusions}

C. setosus produces larger, energy-richer eggs at lower temperatures. This higher investment in the single offspring appears to be an energetic necessity due to the reduced metabolic efficiency of egg development at low temperatures and thus is only partly carried over to later larval stages.

\section{Acknowledgements}

We would like to thank the European Commission for supporting the CENSOR project within the FP6-INCO-STREP programme (contract number 511071). Special thanks are due to Marcelo E. Oliva, JuanPablo Cumillaf, Alejandro Riedemann, and Andres Surot for supporting experimental work carried out in Chile. S.F. is thankful to the German Academic Exchange Service (DAAD) for providing a research grant for his stay in Puerto Montt. This is CENSOR publication number 0377. [SS]

\section{References}

Amsler, M.O.L., George, R.Y., 1984. Seasonal variation in the biochemical composition of the embryos of Callinectes sapidus Rathbun. J. Crustac. Biol. 44, 546-553.

Anger, K., 2001. The Biology of Decapod Crustacean Larvae. A. A. Balkema, pp. 1-420.

Anger, K., Dawirs, R.R., 1982. Elemental composition (C, N, H) and energy in growing and starving larvae of Hyas araneus (Decapoda, Majidae). Fish. Bull. U.S. 80, 419-433.

Barnes, H., 1965. Studies in the biochemistry of cirripede eggs. I. Changes in the general biochemical composition during development of Balanus balanoides and B. balanus. J. Mar. Biol. Assoc. U.K. 45, 321-339.

Brillon, S., Lambert, Y., Dodson, J., 2005. Egg survival, embryonic development, and larval characteristics of northern shrimp (Pandalus borealis) females subject to different temperature and feeding conditions. Mar. Biol. 147, 895-911.

Brooks, S., Tyler, C.R., Sumpter, J.P., 1997. Egg quality in fish: what makes a good egg? Rev. Fish Biol. Fisheries 7, 387-416.

Calado, R., Rosa, R., Nunes, M.L., Narciso, L., 2005. Amino and fatty acid dynamics of Lysmata seticaudata (Decapoda: Hippolytidae) embryos during early and late reproductive season. Mar. Biol. 147, 341-351.

Chapelle, S., 1986. Aspects of phospholipid metabolism in crustaceans as related to environmental temperatures and salinities. Comp. Biochem. Physiol. 84B, 423-439.

Clarke, A., 1992. Reproduction in the cold: Thorson revisited. Invertebr. Reprod. Dev. 22 $175-184$.

Clarke, A., Brown, J.H., Holmes, L.J., 1990. The biochemical composition of eggs from Macrobrachium rosenbergii in relation to embryonic development. Comp. Biochem. Physiol. 96B, 505-511.

Dalsgaard, J., John, M.S., Kattner, G., D. M.-N., W . H., 2003. Fatty acid trophic markers in the pelagic marine environment. Adv. Mar. Biol. 46, 225-340.

Farkas, T., 1979. Adaptation of fatty acid compositions to temperature - a study on planktonic crustaceans. Comp. Biochem. Physiol. 64B, 71-76.

Figueiredo, J., Penha-Lopez, G., Anto, J., Narciso, L., Lin, J., 2008a. Potential fertility and egg development (volumen, water, lipid, and fatty acid content) through embryogenesis of Uca rapax (Decapoda: Brachyura: Ocypodidae). J. Crustac. Biol. 28, 528-533.

Figueiredo, J., Penha-Lopez, G., Anto, J., Narciso, L., Lin, J., 2008b. Fecundity, brood loss and egg development through embryogenesis of Armases cinereum (Decapoda: Grapsidae). Mar. Biol. 154, 287-294.

Fischer, S., Thatje, S., 2008. Temperature-induced oviposition in the brachyuran crab Cancer setosus along a latitudinal cline: aquaria experiments and analysis of field data. J. Exp. Mar. Biol. Ecol. 357, 157-164.

Fischer, S., Thatje, S., Brey, T., 2009. Early egg traits in Cancer setosus (Decapoda, Brachyura): effects of temperature and female size. Mar. Ecol. Prog. Ser. 377, 193-202.

García-Guerrero, M., Villarreal, H., Racotta, I.S., 2003. Effect of temperature on lipids, proteins, and carbohydrates levels during development from egg extrusion to juvenile stage of Cherax quadricarinatus (Decapoda: Parastacidae). Comp. Biochem. Physiol. 135A, 147-154.

Gardner, C., 2001. Composition of eggs in relation to embryonic development and female size in giant crabs [Pseudocarcinus gigas (Lamarck)]. Mar. Freshw. Res. 52, 333-338.

Giménez, L., 2002. Effects of prehatching salinity and initial larval biomass on survival and duration of development in the zoea 1 of the estuarine crab, Chasmagnathus granulata, under nutritional stress. J. Exp. Mar. Biol. Ecol. 270, 93-110.

Giménez, L., 2006. Phenotypic links in complex life cycles: conclusions from studies with decapod crustaceans. Integr. Compar. Biol. 46, 615-622.

Giménez, L., Anger, K., 2001. Relationships among salinity, egg size, embryonic development, and larval biomass in the estuarine crab Chasmagnathus granulata Dana, 1851. J. Exp. Mar. Biol. Ecol. 260, 241-257.

Green, J., 1965. Chemical embryology of the Crustacea. Biol. Rev. 40, 580-600.

Hadfield, M.G., Strathmann, M.F., 1996. Variability, flexibility and plasticity in life histories of marine invertebrates. Oceanol. Acta 19, 323-334. 
Harrison, K.E. 1990. The role of nutrition in maturation, reproduction and embryonic development of decapod crustaceans: a review. J. Shellfish Res. 9, 1-28.

Heming, T.A., 1982. Effects of temperature on utilization of yolk by Chinook salmon (Oncorhynchus tsawytscha) eggs and alevines. Can. J. Fish. Aquat. Sci. 39, 184-190.

Holland, D.L., 1978. Lipid reserves and energy metabolism in the larvae of benthic marine invertebrates. In: Malins, D.C., Sargent, J.R. (Eds.), Biochemical and Biophysical Perspectives in Marine Biology. Academic Press, London, pp. 85-119.

Jaeckle, W.B., 1995. Variation in the size, energy content, and biochemical composition of invertebrate eggs: correlates to the mode of larval development. In: McEdward, L. (Ed.), Ecology of Marine Invertebrate Larvae. CRC Press, Boca Raton, pp. 50-77.

Kattner, G., Fricke, H.S.G., 1986. Simple gas liquid chromatographic method for the simultaneous determination of fatty acids and alcohols in wax esters of marine organisms. J. Chromatogr. 361, 263-268.

Kunisch, M., Anger, K., 1984. Variation in development and growth rates of larval and juvenile spider crabs Hyas araneus reared in the laboratory. Mar. Ecol. Prog. Ser. 15 , 293-301.

Morais, S., Narciso, L., Calado, R., Nunes, M.L., Rosa, R., 2002. Lipid dynamics during the embryonic development of Plesionika martia martia (Decapoda; Pandalidae), Palaemon serratus and P. elegans (Decapoda; Palaemonidae): relation to metabolic consumption. Mar. Ecol. Prog. Ser. 242, 195-204.

Pandian, T.J., 1967. Changes in chemical composition and caloric content of developing eggs of the shrimp Crangon crangon. Helgol. Meeresunters. 16, 216-224.

Pandian, T.J., 1970. Ecophysiological studies on the developing eggs and embryos of the European lobster Homarus gammarus. Mar. Biol. 5, 154-167.

Pandian, T.J., 1994. 3. Arthropoda-Crustacea. In: Adiyodi, K.G., Adiyodi, R.G. (Eds.) Reproductive Biology of Invertebrates. Oxford \& IBH Publ. Co. PVT Ltd., New Delhi.

Pandian, T.J., Schumann, K.-H., 1967. Chemical composition and caloric content of egg and zoea of the hermit crab Eupagurus bernhardus. Helgol. Meeresunters. 16, 225-230.

Petersen, S., Anger, K., 1997. Chemical and physiological changes during the embryonic development of the spider crab, Hyas araneus L. (Decapoda: Majidae). Comp. Biochem. Physiol. 117B, 299-306.

Rathbun, M.J., 1930. The cancroid crabs of America of the families Euryalidae, Portunidae, Atelecyclidae, Cancridae and Xanthidae. Smithsonian Inst. United States Nat. Museum Bull. 152, 1-609.

Rosa, R., Calado, R., Andrade, A.M., Narciso, L., Nunes, M.L., 2005. Changes in amino acid and lipids during embryogenesis of European lobster, Homarus gammarus (Crustacea: Decapoda). Comp. Biochem. Physiol. 140B, 241-249.
Rosa, R., Calado, R., Narciso, L., Nunes, M.L., 2007. Embryogenesis of decapod crustaceans with different life history traits, feeding ecologies and habitats: a fatty acid approach. Mar. Biol. 151, 935-947.

Sasaki, G.C., Capuzzo, J.M.D., Biesot, P., 1986. Nutritional and bioenergetic considerations in the development of the American lobster Homarus americanus. Can. J. Fish. Aquat. Sci. 43, 2311-2319.

Shirley, S.M., Shirley, T.C., Rice, S.D., 1987. Latitudinal variation in the Dungeness crab Cancer magister: zoeal morphology explained by incubation temperature. Mar. Biol. 95, 371-376.

Smith, G.G. Ritar, A.J. Thompson, P.A., Dunstan, G.A., Brown, M.R. 2002. The effect of embryo incubation temperature on indicators of larval viability in stage 1 phyllosoma of the spiny lobster, Jasus edwardsii. Aquaculture 209, 157-167.

Sokal, R.R., Rohlf, F.J., 1995. Biometry: The Principles and Practice of Statistics in Biological Research. W. H. Freeman and Company, New York. 887 pp.

Thatje, S., Bacardit, R., 2000. Morphological variability in larval stages of Nauticaris magellanica (A. Milne-Edwards, 1891)(Decapoda: Caridea: Hippolytidae) from South American waters. Bull. Mar. Sci. 66, 375-398.

Thatje, S., Hillenbrand, C.D., Larter, R., 2005. On the origin of Antarctic marine benthic community structure. Trends Ecol. Evol. 20, 534-540.

Turner, R.L., Lawrence, J.M., 1979. Volume and composition of echinoderm eggs: implications for the use of egg size in life history models. In: Stancyk, S.E. (Ed.), Reproductive Ecology of Marine Invertebrates. University of South Carolina Press, Columbia, pp. 25-40.

Wehrtmann, I.S., Kattner G. 1998. Changes in volume, biomass, and fatty acids of developing eggs in Nauticaris magellanica (Decapoda: Caridea): a latitudinal comparison. J. Crustac. Biol. 18, 413-422.

Wehrtmann, I.S., Lopez, G.A., 2003. Effects of temperature on the embryonic development and hatchling size of Betaeus emarginatus (Decapoda: Caridea: Alpheidae). J. Nat. Hist. 37, 2165-2178.

Weiss, M., Heilmayer, O., Brey, T., Thatje, S., in press. Influence of temperature on the larval development and elemental composition of the cancrid crab, Cancer setosus (Molina 1782) from Pacific South America. J. Exp. Mar. Biol. Ecol.

Wiegand, M.D., 1996. Composition, accumulation and utilization of yolk lipids in teleost fish. Rev. Fish Biol. Fisheries 6, 259-286.

Yampolsky, L.J., Schreiner, S.M., 1996. Why larger offspring at lower temperatures? A demographic approach. Am. Nat. 147, 86-100. 